\title{
Clearance of Deposited Silicon Carbide Whisker from Rat Lungs Inhaled during a 4-Week Exposure
}

\author{
Izumi AkIYAma $^{1}$, Akira Ogami ${ }^{1}$, Takako OYabu ${ }^{1}$, Hiroshi YAmato $^{1}$, Yasuo Morimoto ${ }^{2}$ and \\ Isamu TANAKA ${ }^{1}$
}

${ }^{1}$ Department of Environmental Health Engineering and ${ }^{2}$ Department of Occupational Pneumology, Institute of Industrial Ecological Sciences, University of Occupational and Environmental Health, Japan

\begin{abstract}
Clearance of Deposited Silicon Carbide Whisker from Rat Lungs Inhaled during a 4-Week Exposure: Izumi Akıуama, et al. Department of Environmental Health Engineering, Institute of Industrial Ecological Sciences, University of Occupational and Environmental HealthPulmonary deposition and the clearance of deposited fiber particles from lungs are key determinant factors in assessing potential carcinogenicity and fibrogenicity. Forty-two Wistar male rats (9 wk old) were exposed to silicon carbide whisker (SiCW) for $6 \mathrm{~h} / \mathrm{d}, 5 \mathrm{~d} / \mathrm{wk}$ for 4 wk. The mass median aerodynamic diameter was 2.5 $\mu \mathrm{m}$ as detected by an Andersen sampler, and the geometric mean fiber diameter and length determined by a scanning electron microscope were 0.4 and 2.2 $\mu \mathrm{m}$, respectively. The daily average exposure concentrations were $10.4 \pm 0.5 \mathrm{mg} / \mathrm{m}^{3}$ ( $214 \pm 31$ fibers/ $\mathrm{m} /$ ) during the exposure period. The rats were sacrificed after $3 \mathrm{~d}, 2 \mathrm{wk}, 1,2,3,6$ and 12 months after 4-wk exposure. At the time of sacrifice, the wet lung weights and the deposited SiCW amounts in the lungs were measured by an $X$ ray reference method. The amount of SiCW deposited was $0.60 \pm 0.09 \mathrm{mg} 3 \mathrm{~d}$ after a 4-wk exposure. The apparent deposition fraction was $4.8 \pm 0.7(\%)$. During the clearance period, the amount of SiCW deposited in the rat lungs decreased exponentially with the increasing duration of the clearance period. The biological half time in the onecompartment model was determined to be 4.0 months which is similar to the values for glass fiber, potassium titanate whisker and aluminium-silicate ceramic fiber under similar exposure conditions.

(J Occup Health 2003; 45: 31-35)
\end{abstract}

Key words: Silicon carbide whisker, Inhalation, Lung burden, Biopersistence, Deposition, Clearance

Received June 11, 2002; Accepted Oct 9, 2002

Correspondence to: I. Akiyama, Occupational health care office, Mishima plant, Toray Industries, Inc., 4845 Mishima, Shizuoka 411 8652, Japan
It has been shown that occupational exposure to various types of asbestos may lead to asbestosis, bronchial cancer, and pleural and peritoneal mesotheliomas. To avoid these diseases, newer man-made mineral fibers (MMMFs) with greatly increased toughness and strength have been gradually developed. Because of their improved properties, a number of MMMFs, and especially silicon carbide whisker ( $\mathrm{SiCW}$ ), have become increasingly important as they are used in a variety of products such as ceramic seals, sandblast nozzles and structural materials for use at high temperatures ${ }^{1)}$. Until recently, very little data on the health effects of SiCW were available. Indeed, literature on the subject from the American Conference of Governmental Industrial Hygienists focuses mainly on silicon carbide dust used in abrasives in industry rather than on silicon carbide whisker $^{2}$. In the previous paper ${ }^{3)}$ we showed that SiCW may have a minor effect on the rat lung in the six months after 4-wk exposure.

The present studies generally attempt to relate measured environmental concentrations of MMMF to an observed pathological effect, but an intermediate step in establishing dose-response relationships is to determine how much of the inhaled MMMF is deposited in the lungs, that is the lung burden. The observed biological effect can be related more directly to the lung burden than to the environmental concentration.

In this study, 42 Wistar male rats were exposed to one of the MMMFs, silicon carbide whisker ( $\mathrm{SiCW}$ ), by inhalation for $6 \mathrm{~h} / \mathrm{d}, 5 \mathrm{~d} / \mathrm{wk}$ for $4 \mathrm{wk}$. The lung burden after the exposure and the clearance of deposited SiCW from rat lungs were measured.

\section{Experimental Design}

The exposure system and the experimental procedure have been described elsewhere ${ }^{4,5)}$.

The experimental conditions are summarized in Table 1. The SiCW (CAS No. 409-21-2) used in this experiment 
Table 1. Experimental conditions

\begin{tabular}{ll}
\hline Test fiber & Silicon carbide whisker \\
Exposure condition & $6 \mathrm{~h} / \mathrm{d}$ and $5 \mathrm{~d} / \mathrm{wk}$ for $4 \mathrm{wk}$ \\
Mass concentration & $10.4 \pm 0.5 \mathrm{mg} / \mathrm{m}^{3}$ \\
Count cocentration & $214 \pm 31 \mathrm{fibers} / \mathrm{m} l$ \\
Mass median aerodynamic dimeter (GSD) & $2.5 \mu \mathrm{m}(2.7)$ \\
Geometric mean fiber length (GSD) $^{*}$ & $2.2 \mu \mathrm{m}(1.9)$ \\
Geometric mean fiber diameter (GSD) $^{*}$ & $0.4 \mu \mathrm{m}(1.6)$ \\
\hline
\end{tabular}

*GSD ; Geometric standard deviation

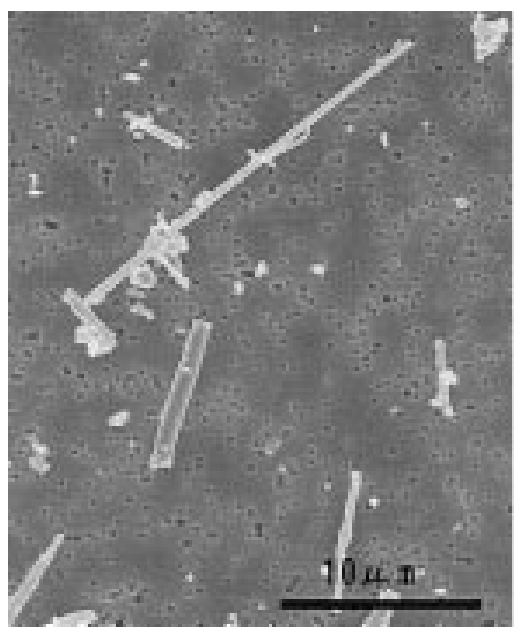

$\mathrm{SiCW}$ in exposure chamber

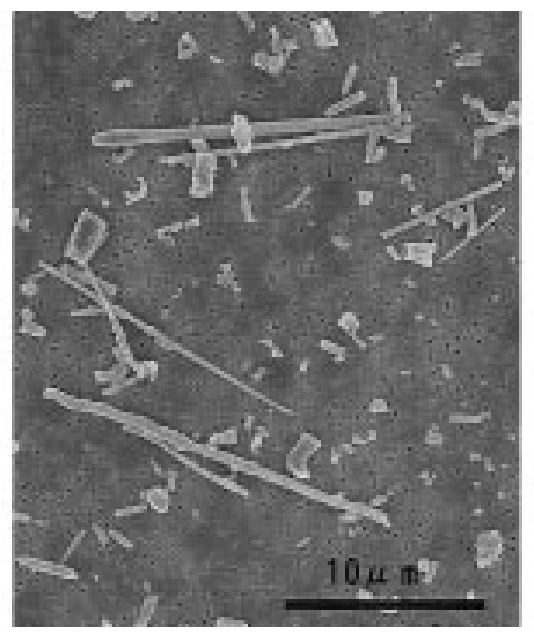

Ashed SiCW in rat lungs $3 \mathrm{~d}$ after exposure

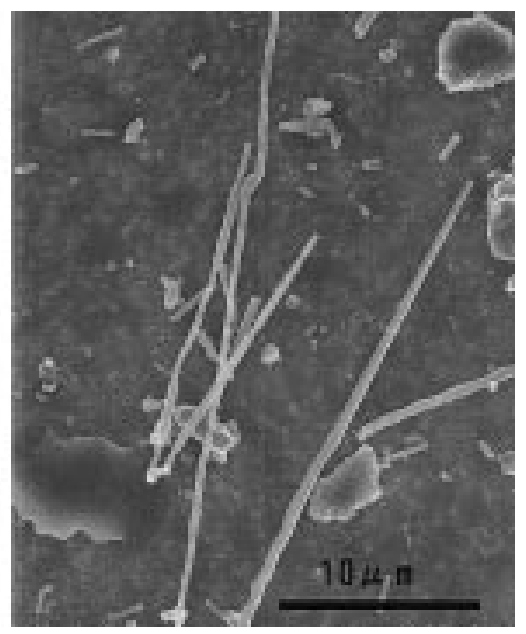

Ashed SiCW in rat lungs 12 months after exposure

Fig. 1. $\mathrm{SiCW}$ in exposure chamber and the ashed $\mathrm{SiCW}$ in rat lungs after exposure

was commercially purchased by Tokai Carbon Co.(Japan). The type of SiCW was TWS-100. The chemical composition was $98 \% \mathrm{SiC}$. Seventy-seven male Wistar rats (9-wk old at the start of exposure) were used in this study. They were randomly allocated to control and exposure groups. Forty-two rats were exposed to $\mathrm{SiCW}$ for $6 \mathrm{~h} / \mathrm{d}, 5 \mathrm{~d} / \mathrm{wk}$ for $4 \mathrm{wk}$. The controls (35 rats) were exposed to clean air in identical, adjacent chambers under similar conditions of flow, temperature and humidity.

The SiCW concentration in the chamber was monitored continuously by a light scattering method (Dust Monitor AP-632, Shibata Scientific Technology Ltd., Japan). The mass concentration of SiCW was measured gravimetrically at daily intervals by the isokinetic suction of air through a glass fiber filter. The daily average exposure mass concentrations were $10.4 \pm 0.5 \mathrm{mg} / \mathrm{m}^{3}$.

The fiber count concentration was measured by means of an asbestos sampler (Air Monitoring Cassette Z008BA, Zefon Analytical Accessories, USA). The daily average exposure count concentrations were $214 \pm 31$ fibers $/ \mathrm{m} l$ during the exposure period. The mass median aerodynamic diameter (MMAD) and the geometric standard deviation (GSD) of the $\mathrm{SiCW}$ in the exposure chamber were measured by means of using an Andersen cascade impactor (Model 3351, Kanomax, Japan). The geometric mean fiber diameter and length of $\mathrm{SiCW}$ in the exposure chamber were determined with a scanning electron microscope (S-4500, Hitachi, Japan) and image analysis software (NIH image, NIH, USA) on a computer.

The rats were sacrificed $3 \mathrm{~d}, 2 \mathrm{wk}, 1,2,3,6$ and 12 months after a 4 -wk exposure. At each sacrifice time, 5 or 12 rats in the exposure groups and 5 rats in the controls were used. The body and wet organ weights (lungs, livers, kidneys and spleens) were measured.

The weighed lungs were ashed with acid solution ( $\mathrm{HNO}_{3}$ and $\mathrm{H}_{2} \mathrm{O}_{2}$ ) by a microwave ashing method (mls 1,200 mega, Milestone, Italy). After ashing, the samples were suspended in distilled water and deposited on a 0.2 $\mu \mathrm{m}$ pore size membrane filter (Micropore, USA) by filtration. SiCW concentrations were measured by an Xray diffraction method (MO3XHF, Mac Sci., USA). 


\section{Results and Discussion}

\section{Ashed $\mathrm{SiCW}$}

Before starting this experiment, we checked that there was no difference between the weight of the SiCW before and after the ashing. Fig. 1 shows the SiCW in the exposure chamber and the ashed SiCW $3 \mathrm{~d}$ and 12 months after 4-wk exposure.
Body and organ weights

Table 2 shows the body weights and the wet organ weights at each sacrifice time. There were no significant differences between the exposed rats and the controls in the body weights and wet organ weights.

\section{Lung burden}

Figure 2 shows the diffraction pattern of the SiCW used in this experiment determined by the X-ray diffraction method. The concentration of SiCW was

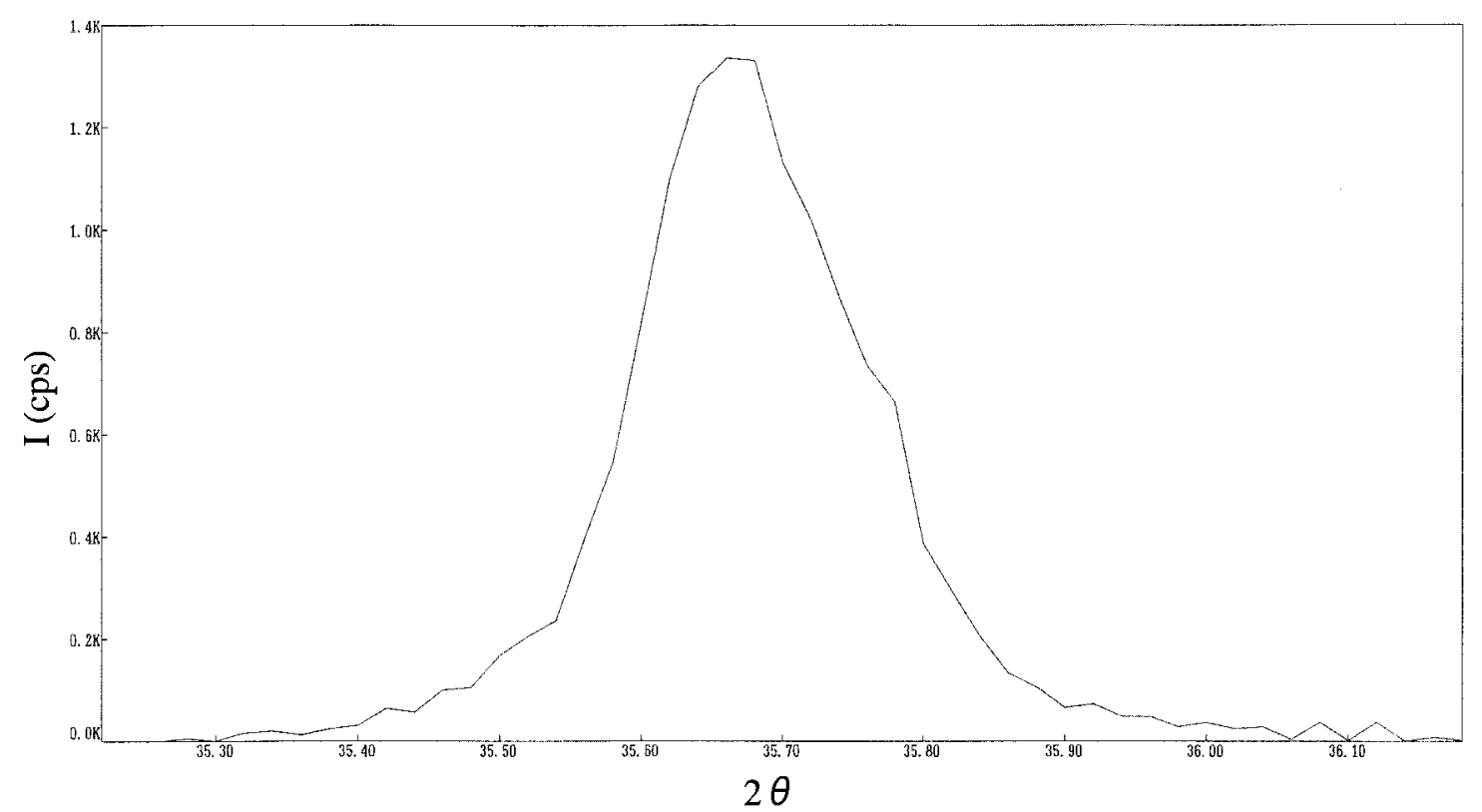

Fig. 2. Typical X-ray diffraction pattern of ashed SiCW

Table 2. Body and wet organ weights after exposure

\begin{tabular}{|c|c|c|c|c|c|c|c|}
\hline & & $\begin{array}{c}\text { Number } \\
\text { of rats }\end{array}$ & $\begin{array}{l}\text { Body } \\
\text { (g) }\end{array}$ & $\begin{array}{l}\text { Lung } \\
\text { (g) }\end{array}$ & $\begin{array}{l}\text { Liver } \\
(\mathrm{g})\end{array}$ & $\begin{array}{c}\text { Kidney } \\
\text { (g) }\end{array}$ & $\begin{array}{l}\text { Spleen } \\
(\mathrm{g})\end{array}$ \\
\hline \multirow[t]{2}{*}{$3 \mathrm{~d}$} & $\mathrm{E}$ & 5 & $362.8 \pm 9.1$ & $1.56 \pm 0.14$ & $9.8 \pm 0.7$ & $2.3 \pm 0.1$ & $0.8 \pm 0.2$ \\
\hline & $\mathrm{C}$ & 5 & $381.8 \pm 18.6$ & $1.40 \pm 0.16$ & $10.6 \pm 1.1$ & $2.4 \pm 0.2$ & $0.9 \pm 0.1$ \\
\hline \multirow[t]{2}{*}{$2 \mathrm{wk}$} & $\mathrm{E}$ & 5 & $414.4 \pm 21.3$ & $1.53 \pm 0.14$ & $12.0 \pm 1.4$ & $2.5 \pm 0.2$ & $0.8 \pm 0.1$ \\
\hline & $\mathrm{C}$ & 5 & $428.2 \pm 18.4$ & $1.50 \pm 0.09$ & $11.0 \pm 0.9$ & $2.6 \pm 0.1$ & $0.8 \pm 0.1$ \\
\hline \multirow[t]{2}{*}{1 month } & $\mathrm{E}$ & 5 & $444.2 \pm 22.6$ & $1.52 \pm 0.04$ & $11.1 \pm 0.4$ & $2.6 \pm 0.2$ & $0.9 \pm 0.1$ \\
\hline & $\mathrm{C}$ & 5 & $433.4 \pm 25.7$ & $1.46 \pm 0.04$ & $10.6 \pm 0.9$ & $2.5 \pm 0.1$ & $0.8 \pm 0.1$ \\
\hline \multirow[t]{2}{*}{2 months } & $\mathrm{E}$ & 5 & $466.2 \pm 33.3$ & $1.51 \pm 0.09$ & $12.2 \pm 1.3$ & $2.7 \pm 0.3$ & $0.9 \pm 0.1$ \\
\hline & $\mathrm{C}$ & 5 & $445.2 \pm 16.4$ & $1.56 \pm 0.09$ & $10.8 \pm 0.4$ & $2.6 \pm 0.1$ & $0.8 \pm 0.1$ \\
\hline \multirow[t]{2}{*}{3 months } & $\mathrm{E}$ & 5 & $503.8 \pm 14.4$ & $1.53 \pm 0.07$ & $12.6 \pm 1.2$ & $2.9 \pm 0.3$ & $0.8 \pm 0.1$ \\
\hline & $\mathrm{C}$ & 5 & $505.0 \pm 29.1$ & $1.44 \pm 0.07$ & $11.9 \pm 0.6$ & $2.4 \pm 0.2$ & $0.8 \pm 0.1$ \\
\hline \multirow[t]{2}{*}{6 months } & $\mathrm{E}$ & 5 & $568.2 \pm 31.9$ & $1.72 \pm 0.17$ & $13.4 \pm 0.8$ & $2.6 \pm 0.1$ & $0.9 \pm 0.1$ \\
\hline & $\mathrm{C}$ & 5 & $598.2 \pm 66.8$ & $1.72 \pm 0.17$ & $14.7 \pm 1.8$ & $2.8 \pm 0.2$ & $0.9 \pm 0.1$ \\
\hline \multirow[t]{2}{*}{12 months } & $\mathrm{E}$ & 12 & $617.6 \pm 60.5$ & $1.87 \pm 0.14$ & $14.2 \pm 2.0$ & $3.2 \pm 0.1$ & $1.0 \pm 0.1$ \\
\hline & $\mathrm{C}$ & 5 & $608.8 \pm 56.3$ & $1.73 \pm 0.22$ & $13.5 \pm 1.4$ & $2.8 \pm 0.4$ & $0.9 \pm 0.1$ \\
\hline
\end{tabular}

E: Exposure group , C: Control group 
Table 3. Lung burden of $\mathrm{SiCW}$ after the exposure

\begin{tabular}{lc}
\hline & $(\mathrm{mg})$ \\
\hline $3 \mathrm{~d}$ & $0.60 \pm 0.09$ \\
$2 \mathrm{wk}$ & $0.52 \pm 0.08$ \\
1 month & $0.44 \pm 0.05$ \\
2 months & $0.36 \pm 0.05$ \\
3 months & $0.34 \pm 0.09$ \\
6 months & $0.19 \pm 0.05$ \\
12 months & $0.07 \pm 0.03$ \\
\hline
\end{tabular}

determined by the density of the main diffraction angle $\left(2 \theta=35.7^{\circ}\right)$. The diffraction beam intensity was integrated between $35.2^{\circ}$ and $36.2^{\circ}$. The measured amounts of SiCW deposited in rat lungs are shown in Table 3 . In this experiment, the maximum $\mathrm{SiCW}$ content in rat lung was $0.60 \pm 0.09 \mathrm{mg}$ in the exposed rat group.

The apparent deposition fraction in the lungs was calculated by the ratio of the measured $\mathrm{SiCW}$ content in the lungs to the estimated amount of the inhaled SiCW during the exposure. The estimated amount of total inhaled $\mathrm{SiCW}$ is calculated ${ }^{6}$ by average exposure concentration $\times$ total exposure time $\times$ respiratory volume ${ }^{7}$.

The estimated amount of total inhaled whisker was $12.5 \pm 0.2(\mathrm{mg})$. The apparent deposition fraction was $4.8 \pm 0.7(\%)$. This value coincided with the apparent deposition fraction in rat lungs which inhaled by various types of fibers and particles ${ }^{8)}$.

\section{Clearance of the deposited $\mathrm{SiCW}$ in the rat lungs}

It may be recognized that inhaled fibers and particles are eliminated from lungs by dissolution in the lung fluid and translocation by macrophages. $\mathrm{SiCW}$ is known to be insoluble, and over $90 \%$ of the exposed SiCW was less than $10 \mu \mathrm{m}$ because the geometric mean fiber length was $2.2 \mu \mathrm{m}$ (GSD1.9) in this experiment. As the SiCW in the lungs would be phagocytized and cleared by macrophages, the one-compartment model was assumed to evaluate the clearance of fibers. Fig. 3 shows that the $\mathrm{SiCW}$ deposited in the rat lungs decreased exponentially with the increase in length of the clearance period after the 4-wk exposure. The solid line in Fig. 3 was calculated from the one-compartment model with the biological half time of 4.0 months $\left(\mathrm{R}^{2}=0.9\right)$.

In the previous paper ${ }^{8)}$, we showed that the biological half times were almost the same (1.5-4 months) when the lung burden was lower than $0.65 \mathrm{mg}$. The relationship between the biological half time and the amount of fibers deposited in rat lungs in this experiment coincided with those in the previous experiments obtained by using glass fiber, aluminum-silicate ceramic fiber and potassium titanate whisker, but we reported in the previous paper that $\mathrm{SiCW}$ may have a minor histopathological effect on rat lung in the six months ${ }^{3)}$. At this stage, the effects of the amount deposited and the biological half time on the histopathological change are not yet clear. We believe that it is important to find these effects. The relationship

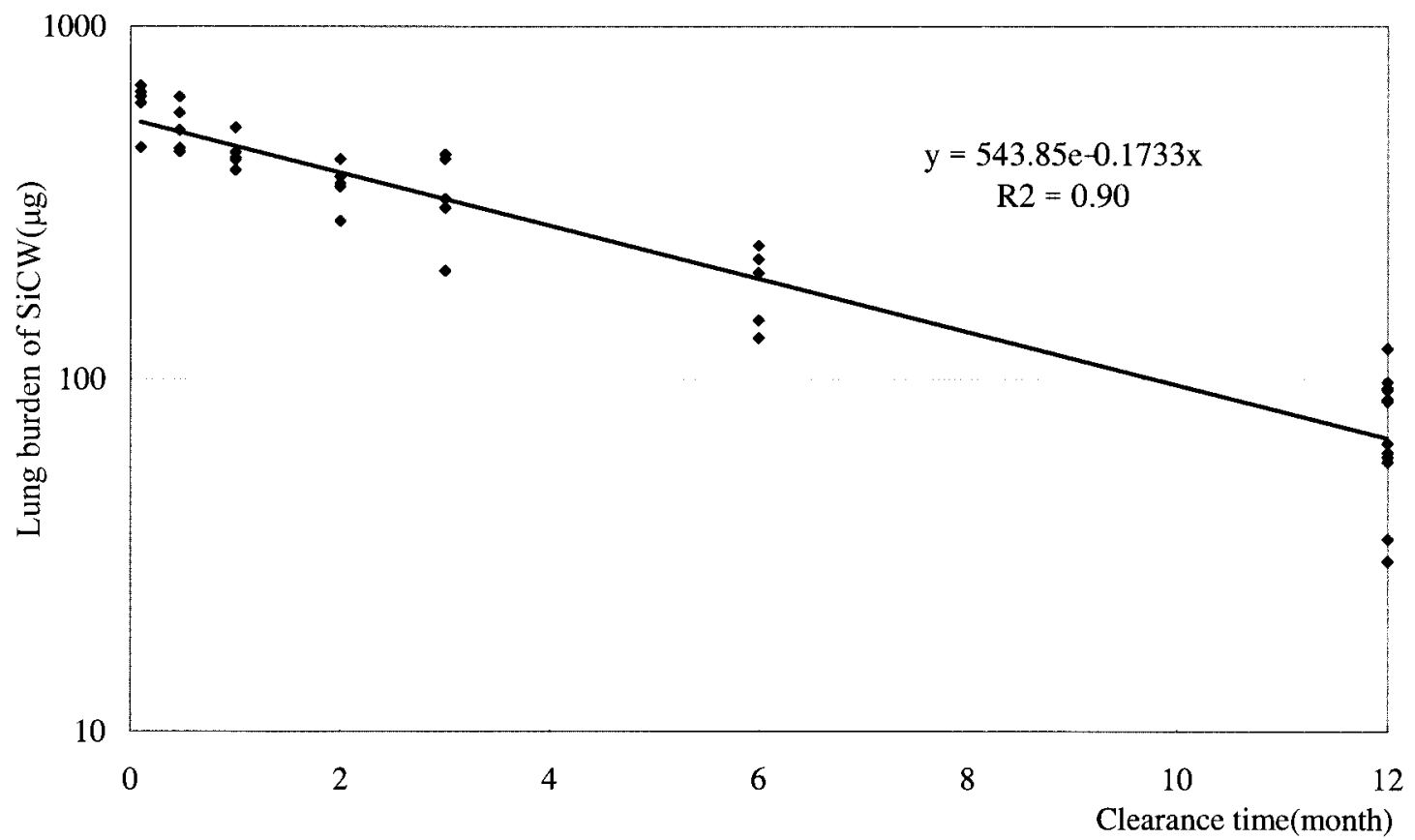

Fig. 3. Lung burden of SiCW inhaled for the 4-week exposure 
between the amount deposited and the biological half time and the histopathological change should be investigated continuously.

\section{Conclusion}

Wistar male rats were exposed to SiCW(length: 2.2 $\mu \mathrm{m}$, diameter: $0.4 \mu \mathrm{m}$, MMAD: $2.5 \mu \mathrm{m}$ ) for $4 \mathrm{wk}$. The $\mathrm{SiCW}$ deposited in rat lungs was determined to be 0.6 $\mathrm{mg}$ by the X-ray diffraction method after the microwave ashing with acid. The apparent deposition fraction in the rat lungs was $4.8 \pm 0.7(\%)$ in this experiment. The biological half time of deposited SiCW in rat lungs was 4.0 months. Deposition and clearance are important factors in the inhalation hazard of fibrous particles and should be monitored continuously.

\section{References}

1) C A Lapin, D K Craig, M G Valerio, J B McCandless and R Bogoroch: A subchronic inhalation toxicity study in rats exposed to silicon carbide whiskers. Fundm Appl Toxicol 16, 126-146 (1991)

2) Silicon carbide in Documentation of the threshold limit values. Cincinnati, Ohio: ACGIH (2000)
3) A Ogami, Y Morimoto, H Yamato, T Oyabu, I Akiyama and I Tanaka: Short term effect of silicon carbide whisker to the rat lung. Ind Health 39, 175-182 (2001)

4) I Tanaka, T Oyabu, S Ishimatsu, H Hori, T Higashi and $\mathrm{H}$ Yamato: Pulmonary deposition and clearance of glass fiber in rat lungs after long-term inhalation. Environ Health Perspect 5, 215-216 (1994)

5) H Hori,T Kasai, J Haratake, $S$ Ishimatsu, T Oyabu, $H$ Yamato, T Higashi and I Tanaka: Biological effects of inhaled magnesium sulphate whiskers in rats. Occup Environ Med 51, 492-499 (1994)

6) I Tanaka: Respiratory tract deposition and clearance of inhaled particles in laboratory animals. J Aerosol Res Japan 3, 104-110 (1988) (in Japanese)

7) A G Guyton: Measurement of the respiratory volumes of laboratory animals. Am J Physiol, 150, 70-79 (1947)

8) T Oyabu, Y Morimoto, I Tanaka: Factors related to lung injury induced by silica. J. Aerosol Res. Japan16, 275-279 (2001) (in Japanese)

9) T Oyabu, I Tanaka, S Ishimatsu, H Yamato, Y Morimoto, T Tsuda, H Hori and T Higashi: Effect of exposure period and lung burden on clearance rate of inhaled aluminum-silicate ceramic fibre from rat lung. Ann Occup Hyg 41, 210-212 (1997) 